\title{
Predicting levodopa-induced dyskinesia
}

\author{
Predição de discinesia induzida por levodopa \\ Peter KEMPSTER ${ }^{1,2}$
}

${ }^{1}$ Monash Medical Centre, Neurosciences Department, Clayton, Australia.

${ }^{2}$ Monash University, School of Clinical Sciences, Department of Medicine, Clayton, Australia. Peter KEMPSTER (iD https://orcid. org/0000-0002-6321-3930

Correspondence: Peter Kempster; E-mail:Peter.Kempster@ monashhealth.org

Conflict of interest: There is no conflict of interest to declare.

Received on February 14, 2020

Accepted on February 20, 2020

\section{(cc) BY}

$\mathrm{T}$ he first detailed description of levodopa-induced dyskinesia came from George Cotzias, pioneer of practical levodopa therapy for Parkinson's disease (PD). His 1969 paper reported results of treatment in levodopa-naïve patients who were, on average, a decade into their disease course. Dyskinesia, which developed in $50 \%$, began soon after titration to an effective levodopa dose ${ }^{1}$. This was, of course, the point in the history of levodopa when the effects of length of treatment could most easily be discerned from those of length of PD. Cotzias observed that the most severe involuntary movements occurred among patients with the greatest durations of disease. Furthermore, he noticed a clear association between dyskinesia and the degree of motor improvement. Publications over the next few years highlighting the twin problems of levodopa - motor fluctuations and dyskinesia - cast quite a long shadow over the drug.

Santos-Lobato and colleagues have, from a cross-sectional statistical analysis of more than 400 Brazilian PD patients's , developed predictive formulae for dyskinesia that draw on clinical features and selective genotyping. Strictly speaking, their system predicts presence of dyskinesia and not its future development, though some elements have prognostic implications. Multivariate modelling yielded 5 independent variables -4 clinical and one genetic. An association with disease duration accords with Cotzias's experience. Predictiveness of age at disease onset reflects the well-established tendency for younger patients to have a longer course with more motor complications. Use of dopamine receptor agonists probably only 'predicts' dyskinesia in the sense that these drugs are often used as early treatment in younger subjects, or are introduced to manage unstable levodopa motor responses. The result that tremor as presenting symptom is actually the strongest predictor of not having dyskinesia is interesting. Disease subtyping is a complex area, though attributes of tremor-dominant PD are usually thought to be slower progression, lesser degrees of bradykinesia and, possibly, a milder dopaminergic deficit ${ }^{3}$. Tremor dominance also encompasses the entity of so-called benign tremulous parkinsonism, and not all subjects who fulfill its definition have the pathological lesions of idiopathic $\mathrm{PD}^{4}$. Participants in this research were genotyped for single nucleotide polymorphisms in a number of genes that have been linked to levodopa-induced dyskinesia in past studies. A polymorphism of the adenosine $\mathrm{A} 2 \mathrm{~A}$ receptor gene was the most predictive genotype. Adenosine $\mathrm{A} 2 \mathrm{~A}$ receptors are present in the basal ganglia, have a modulating effect of dopaminergic neurotransmission, and could plausibly influence dyskinesia in PD. The predictive formula including this genotype was comparable but not superior to one using only the 4 independent clinical variables listed above. It might have been informative to include data relating to the presence of motor fluctuations, which commonly accompany dyskinesia, and to the magnitude of the levodopa motor response.

The authors premise that dyskinesia is an important part of the disease burden in terms of both health care costs and quality of life needs some qualification. Bouts of semi-violent biphasic dystonia and dyskinesia, or motor benefit that is degraded by excessive peak dose involuntary movements, represent serious treatment-related disability. Milder degrees of dyskinesia often appear around the time that wearing off symptoms are first volunteered. Their presence and severity corelates with the magnitude of motor improvement after levodopa test-doses ${ }^{5}$, so they tend to confirm that a patient is obtaining a reasonable dopaminergic motor response. Delaying the commencement of pharmacological treatment or initiating treatment with weaker but more stable dopamine receptor agonists does reduce dyskinesia. But these strategies entail some forgone levodopa motor benefit, and most patients sooner or later require the drug. The authors rightly make the point that better anti-dyskinetic drugs for PD are desirable, and that these predictive formulae should aid recruitment to clinical trials. It is important, though, to have a balanced view about to what degree dyskinesia is the enemy of satisfactory management of PD. Dyskinesia and motor response have a very close relationship once a certain level of dopaminergic nigral cell loss has occurred. 


\section{References}

1. Cotzias GC, Papavasiliou PS, Gellene R. Modification of Parkinsonism--chronic treatment with L-dopa. N Engl J Med. 1969 Feb 13;280(7):337-45. https://doi.org/10.1056/ NEJM196902132800701

2. Santos-Lobato BL, Schucacher-Schuh AF, Rieder CRM, Hutz MH, Borges $V$, Ferraz HB, et al. Diagnostic prediction model for levodopainduced dyskinesia in Parkinson's disease. Arq Neuropsiquiatr. 2020. In press. https://doi.org/10.1590/0004-282X20190191

3. Rajput AH, Voll A, Rajput ML, Robinson CA, Rajput A. Course in Parkinson disease subtypes: a 39-year clinicopathologic study. Neurology. 2009 Jul;73(3):206-12. https://doi.org/10.1212/ WNL.0b013e3181ae7af1
4. Selikhova M, Kempster PA, Revesz T, Holton JL, Lees AJ. Neuropathological findings in benign tremulous Parkinsonism. Mov Disord. 2013 Feb;28(2):145-52. https://doi.org/10.1002/mds.25220

5. Clissold BG, McColl CD, Reardon KR, Shiff M, Kempster PA. Longitudinal study of the motor response to levodopa in Parkinson's disease. Mov Disord. 2006 Dec;21(12):2116-21. https://doi. org/10.1002/mds.21126

6. Rascol O, Brooks DJ, Korczyn AD, De Deyn PP, Clarke CE, Lang AE. A five-year study of the incidence of dyskinesia in patients with early Parkinson's disease who were treated with ropinirole or levodopa. N Engl J Med. 2000 May 18;342(20):1484-91. https://doi.org/10.1056/ NEJM200005183422004 